\title{
A Influência dos Meios de Comunicação no Desenvolvimento da Sexualidade
}

Maria Helena Gouveia ${ }^{1}$ mininas".

Circulam atualmente três tipos principais de revistas ditas "fe-

a. Revistas para a mulher independente economicamente e liberada de preconceitos. Além das qualidades gráfica e redacional, desenvolvem uma pauta basicamente vivencial: artigos, entrevistas, enquetes, cuja tônica é o desenvolvimento da sexualidade feminina, durante tantos anos reprimida. Essas revistas visam ensinar como desenvolver a sexualidade, expressão, no caso, sinônima de: como tirar proveito, como aprender, como ser uma mulher vencedora, com liberdade, dinheiro e sexualmente realizada. Exemplo de alguns títulos: "Como obter cinco orgasmos em meia hora"; "Saiba o que o seu parceiro gosta mais, na cama"; "Descubra detalhadamente a intensidade de suas zonas erógenas".

b. Revistas para as "gatinhas", no caso adolescentes. Seguindo a mesma linha de apresentação visual, enfoca principalmente moda (enfatizando o corpo em primeiro lugar - atualmente minisaias, mini-blusas), valorizando os cuidados com a pele, os cabelos etc. Matérias leves sobre comportamento, medicina e sexo, além de algumas receitinhas fáceis para o lanche, completam estas publicaçães mensais.

c. Outras revistas femininas de grande procura, leitura multiplicada e quase obrigatória nos salões de beleza, são aquelas cujo 
ingrediente principal é a fofoca, alcançando seus objetivos sem perigo de erro. "Quem deixou quem por quem", é infalível. "Quem está grávida de quem", como funciona! E em manchete de capa! "Quem vai "tirar a virgindade de quem" na novela que ocupa o primeiro lugar no IBOPE, é capa fotográfica!

Exceto nas revistas da mulher liberada, nas demais, é preciso notar que beleza, decoração, culinária, medicina e psicologia, na maioria das vezes, aparecem com igual destaque, assim como: "Saiba mais sobre AIDS", "Faça esta mousse de manga e espere os elogios", "Aprenda como preparar um arranjo de flores secas", "Estou casada há quinze anos e a rotina tomou conta de nossas vidas. $\mathrm{O}$ que fazer?", "Gems de ovo nutre e deixa mais brilhantes os seus cabelos"...

Quanto às revistas masculinas, algumas oferecem ótimas reportagens, entrevistas e matérias bem feitas, intercaladas com fotos de mulheres passando forte sensualidade. Outras, de menor importância jornalística, valorizam mais o erotismo e a pornografia.

Além destes canais de comunicação, os cartazes de rua (outdoors) estão em cada esquina, em cada parede estratégica, vendendo toalhas macias envolvendo corpos nus, calcinhas femininas que "deslumbram" os passageiros masculinos, cuecas e passarinhos, desodorantes e perfumes corpo a corpo, maiôs e filtros solares, sorvetes e refrigerantes, peças de automóveis sob o título "ela usa uma peça só" (isto é, a original do carro) etc., tendo sempre como referencial modelos com plástica invejável, ou melhor, um corpo de alta sugestão, e textos de duplo sentido.

\section{II}

Para o leitor que acompanhou a primeira parte deste trabalho, o julgamento poderá ser imediato: trata-se de uma moralista. Portanto, inicio e segunda parte afirmando categoricamente: - absolutamente, não sou! Apenas, jornalismo e publicidade são o meu dia-a-dia. Acompanho de perto aqueles que se dedicam a estas áreas e não entro no mérito, neste artigo, das suss criações, pesquisas, trabalhos e resultados. O meu objetivo é fazer algumas considerações sobre as respostas obtidas por estes meios de comunicação no que diz respeito ao desenvolvimento da sexualidade.

Nas revistas masculinas a ordem é apenas insinuar, porque qualquer artigo ensinando o macho brasileiro a agir corresponde a subestimá-lo na sua virilidade e conseqüentemente perder a 
aceitação de seus leitores. Assim, elas funcionam, quanto à sexualidade, como incentivadoras de suas fantasias eróticas.

Nas revistas femininas para mulheres liberadas, ao contrário, ensinam tudo o que a mulher brasileira ignorava, colocando-a muito à frente do homem, quanto a estas informações "técnicas", possibilitando-as demonstrar claramente seus desejos, e como realizá-los.

Desde então passou a haver um comprometimento do comportamento masculino, gerando inúmeros conflitos. Estou me referindo a dados de pesquisas realizadas com leitores das revistas Nova e Playboy, duas das maiores tiragens da Editora Abril, a maior editora brasileira.

Porém, estas pesquisas foram tabuladas com opiniões de leitores de revistas, isto é, pessoas, no mínimo, com certo nível econômico e cultural, e, na maioria, adultos.

E as demais revistas?

As das donas-de-casa não afetam o tema deste artigo. As das "gatinhas" atuam como despertador de emoções a sensações, sem explicações maiores. Mais um agente para as dúvidas das adolescentes.

E os cartazes de rua? E os programas de televisão vistos por pessoas de todos os níveis, de todas as idades?

\section{III}

É comum ouvir-se das gerações de pais e avós: "Hoje em dia as crianças sabem muito mais que a gente. Vêem tudo na televisão".

\section{IV}

Se considerarmos os meios de comunicação a sua influência no desenvolvimento da sexualidade, chegaremos a alguns dados concretos.

Para os mais velhos, a surpresa de ver assuntos tão íntimos, considerados tabus e, portanto, não elaborados, a surpresa de perderem a individualidade e serem generalizados com a maior facilidade, sem qualquer explicação. Para as gerações mais novas, e convivência diária com esses mesmos assuntos, tão visualinente introduzidos em suas cabeças que desconhecem até a necessidade de qualquer explicação a mais. Tudo é natural. Tudo é normal. O desconhecido ficou tão óbvio. Ir para a cama é tão fácil. Levar uma camisinha no bolso, ou na bolsa, é tão necessário quanto levar um pente. E o 
porquê de tudo isto passa tão rápido e despercebido) quanto mudar de canal e assistir outro programa.

Mas, e a lacuna que permanece entre a cabeça dos telespecta dores e a telinha? E o momento em que esta lacuna aparece na vida real, no desenvolvimento e no desempenho de cada indivíduo?

Os valores estão mudando suas dimensões. Para os mais velhos, roubar, vingar-se, matar podem ser "fortes", mas não são "Indecentes", como cenas de sexo. Para os mais jovens, roubar, vingar-se, matar são fatos concretos. Sexualidade, sexo fazem parte da rotina diária.

\section{V}

Atualmente muito se fala em educação sexual nas escolas, nas famílias. Pesquisas também provam que a maioria das famílias, assim como não foram preparadas quanto à sua sexualidade, também não estão aptas a preparar. E para quê, se com a televisão as crianças já "sabem tudo"? Quanto às crianças e adolescentes, aprender o quê? Só se for com videos e revistinhas de sacanagern (duas das maiores fontes de renda da comunicação) para conhecerem detalhes, estes sim, ainda desconhecidos. Mas, são detalhes...

Todos estes dados nos oferecem a conclusão de que a grande influência dos meios de comunicação no campo da sexualidade não é a conseqüência imediata do que é visto, mas a conseqüência do que não é mostrado.

Isto me faz lembrar uma aula que dei, há alguns anos, a 45 adolescentes que acompanhavam com o maior interesse a minha leitura, entusiasticamente interpretada, de uma história publicada em uma revista de fotonovelas, muito procurada na época. $\mathrm{O}$ enredo, basicamente sempre o mesmo: a história de um moço e uma moça que se apaixonaram. "Por engano", um deles imaginou que o outro o traíra. Separaram-se. Reencontraram-se, "por coincidência", após sete anos, quando tudo foi esclarecido. Em um quadrinho, lia-se: “... e Helena foi embora em prantos". No outro: "Ricardo, decepcionádo, partiu para um curso na Europa". No quadrinho seguinte: “... Passaram-se sete anos. Helena tinha um lindo Marcinho". E como Ricardo havia voltado, desfez-se, "por acaso", o engano, e a história terminava com um romântico beijo 18 x 24, acompanhado pelo suspiro aliviado e feliz de todas as meninas. Foi quando perguntei: Passaram-se sete anos e Helena a Ricardo estavam absolutamente iguais e apaixonados? Ele era um médico (de branco!) lindo e famoso. Ela, uma enfemeira pobre. Como fez para ter seu filho, 
criá-lo a transformá-lo no lindo a saudável Marcinho? O tempo a as dificuldades pelas quais passara não afetaram em nada a sua beleza? E tudo continou como se nada houvesse acontecido?

Não é preciso dizer que a aula terminou com inúmeras perguntas, um alvoroço. E para surpresa minha, as mães, na aula seguinte, perguntavam o que havia acontecido, pois suas filhas que adoravam tais revistas, passaram a criticá-las. levisão.

Isto aconteceu no auge das fotonovelas. Hoje, repete-se na te-

Desligar os aparelhos? Não é solução. Discutir o que é realidade e o que é ficção é muito enriquecedor.

Se, de um lado, a influência dos meios de comunicação no desenvolvimento da sexualidade pode ser maléfico, de outro, é a grande abertura para o diálogo e a aproximação entre pais e filhos. Comentar, por exemplo, que o carnaval de uma atriz de linhas perfeitas e seios invejáveis não é apenas a glória da passarela; conversar mostrando que atrás de uma cena quase real de um parto feliz, estão nove meses de gestação e cuidados; discutir se é preciso ser sempre jovem, lindo, ou linda, para amar intensamente; rever padrões de comportamento; procurar definir o que é amor, o que é uma relação sexual em toda sua intensidade, sem a rapidez dos segundos caríssimos de um canal de televisão; explicar que o uso de um preservativo é recomendável, mas também, como, quando e porque; levantar dúvidas, discutir situações. Trocar experiéncias acontecidas com gerações diferentes. Da mesma forma, revistas como Nova e Playboy deveriam ser lidas por ambos os sexos, tendência, aliás, que vem se registrando progressivamente.

Este novo comportamento, provocado pelo desenvolvimento e abrangência cada vez maior dos meios de comunicação, alertará as "senhoras" leitoras das revistas que se baseiam apenas em moda, beleza, decoração a culinária de que também há outras matérias que poderão prender a sua atenção.

Nos meios de comunicação a informação é maciça, mas também é parcial. E como as pessoas não se dão conta disso, sua influência vem sendo extraordinária no comportamento individual.

\section{VI}

Concluindo, creio poder afirmar, assentada em inúmeras pesquisas e amostragens de todos os segmentos sociais, culturais e econômicos, que a comunicação influencia, a cada segundo, o desenvolvimento da sexualidade de crianças, adolescentes e adultos, 
mas, que esta influência pode também tornar-se altamente positiva se se transformar em um alerta e crescimento para as gerações despreparadas, assim como em um despertar em busca de respostas, para as gerações mais novas. Talvez o melhor argumento para a necessidade da educação sexual.

A invenção é extraordinária. Como usá-la é o complemento, e é indispensável. 